\title{
Antioxidant Activities in Methanolic Extracts of Olea Ferruginea Royle Fruits
}

\author{
R. K. Sharma, N. Sharma, S. S. Samant, S. K. Nandi, and L. M. S. Palni
}

\begin{abstract}
Olea ferruginea Royle is an important multipurpose tree and an underutilized fruit tree crop of Himachal Pradesh, India. The antioxidant potential of fruits of this species has not been properly investigated; therefore, in the present study, total phenolic content and antioxidant capacity of methanolic extracts of fruits of $O$. ferruginea from five populations were investigated. Mature fruits from three different trees of approximately same height and age from various populations (Thalaut, Sapangi, Suind, Kolibehar and Kais) were collected. One gram of fresh fruits was homogenized with $10 \mathrm{ml}$ of $80 \%(\mathrm{v} / \mathrm{v})$ methanol and extracts were analyzed for total phenolic content (mg tannic acid equivalent (TAE)/g fw) and antioxidant capacity [mM of ascorbic acid equivalent (AAE)/g fw of fruit] using 3 in-vitro assays, namely, 1, 1-diphenyl-2-pycrylhydrazyl (DPPH), 2,2'-azinobis, 3-ethylbenzothiazoline-6-sulphonic acid radical scavenging (ABTS) and ferric reducing antioxidant power (FRAP). The total phenolic content in the methanolic fruit extracts among different populations varied between 2.30-3.41 TAE/g fw, and their antioxidant activities using DPPH, FRAP and ABTS assayes among the populations ranged from $0.15-0.24,28.02$ 31.4 and $0.0019-0.0138 \mathrm{AAE} / \mathrm{g}$ fw. The study further showed that ripe fruits of $O$. ferruginea possess significantly higher phenolic content, DPPH and ABTS radical scavenging potential as compared to the raw fruits. On the other hand, raw fruits have significantly higher FRAP activity in comparison to ripe fruits. The study reveals that the ripe fruits of $O$.ferruginea are a rich source of natural antioxidants and can be used as nutraceuticals and should be exploited for commercial purposes.
\end{abstract}

Index Terms-Total phenolics antioxidant capacity, Indian olive, population, fruits.

\section{INTRODUCTION}

Interest in recent years in natural antioxidants from plants is increasing due to their free radical scavenging potential. Several plant based extracts have been screened for investigating their antioxidant and radical scavenging activities [1], [2]. Distributions of phenolics and flavonoids in nature as antioxidants have been reported worldwide [2], [3].

Antioxidants have therapeutic importance as they possess neuroprotective and neurodegerative roles. The main

Manuscript received October 15, 2012; revised December 5, 2012.

This work was supported by G.B. Pant Institute of Himalayan Environment and Development, an autonomous organization of the Ministry of Environment and Forest, Govt. of India, New Delhi.

R. K. Sharma, N. Sharma, and S. S. Samant are with G.B. Pant Institute of Himalayan Environment and Development, Himachal Unit, Mohal-Kullu 175126 (H.P.), India (Phone 01902-225329; Fax: 01902-226347; e-mail: rajeshbhu78@gmail.com, samantss2@rediff mail.com).

S. K. Nandi and L. M. S. Palni are with G.B. Pant Institute of Himalayan Environment and Development, Kosi-Katarmal, Almora 263643 (U.K.), India (e-mail: shyamal_nandi@rediffmail.com, Imspalni@rediffmail.com). characteristic of an antioxidant is the ability to trap free radicals. Antioxidants are categorized into two groups, i.e., exogenous and endogenous. The exogenous group includes dietary phytochemicals (polyphenols, quinones, flavonoids, chatechins, coumarins, terpenoids, etc.) and smaller molecules (ascorbic acid, alpha-tocopherol, beta-carotene, etc.). The endogenous group includes enzyme (superoxide dismutase, catalase, glutathione peroxide, etc.) and trace metals ( $\mathrm{Cu}, \mathrm{Zn}, \mathrm{Mn}, \mathrm{Se}$, etc.)

Indian Himalayan Region is one of the richest biodiversity hotspots on globe and supports a large number of multi-purpose plant species [4]. Olea ferruginea Royle (family: Oleaceae) is a native species of the Himalaya region and grows naturally in the agro-ecosystems. Being one of the six species of Olea, known as Indian Olive (locally known as Kahoo), O. ferruginea is found in Afghanistan, west Nepal, Jammu \& Kashmir and Uttrakhand between 500-2000 m asl. It is a multipurpose, zero-waste and evergreen fruit tree crop providing various uses such as quality fodder, fuel wood, edible fruits and treatment for various ailments. According to Joshi [5] the content of mono-unsaturated fatty acid, particularly oleic acid, ranged from $64.4-67.2 \%$ in seed oil of Indian Olive, slightly higher than its fruit oil.

Therefore, the present study has been carried out to assess the antioxidant activities in methanolic extracts of the fruits of O. ferruginea growing in Kullu, Himachal Pradesh and also to compare the antioxidant activities of both raw and ripe fruits.

\section{MATERIALS AND METHODS}

The present study was carried out in Kullu district of Himachal Pradesh, India during August/September 2011. Five populations of Indian Olive, namely Thalaut, Sapangi, Suind, Kolibehar and Kais were selected and fruit samples from three different trees of the same height and age (each population) were collected in poly bags. The samples of both raw and ripe fruits were also collected from the same tree of Kolibehar population. The samples were brought back to the laboratory and kept at $4^{0} \mathrm{C}$ in the refrigerator for 24 hours. All samples were washed thrice using running tap water to remove dust particles and chopped into small pieces. One gram of fruits was weighted accurately and crushed in $10 \mathrm{ml}$ of $80 \%(\mathrm{v} / \mathrm{v})$ methanol using mortar and pestle. The extract was further kept in the refrigerator at $4^{0} \mathrm{C}$ for $48 \mathrm{~h}$ and then centrifuged at 10,000g; the supernatant was collected and used for the analysis of total phenolic content and antioxidant activities. Similarly, the extracts were prepared from the raw and ripe fruits.

The total phenolic content in methanolic extract of fruits of Indian Olive was determined spectrophotometrically using 
the modified method of Wolfe et al. [6]. One ml aliquot of the extract was mixed with $1 \mathrm{ml}$ of Folin-Ciocalteu Phenol Reagent and $2 \mathrm{ml}$ of $2 \%(\mathrm{w} / \mathrm{v})$ sodium carbonate; the total volume was made up to $10 \mathrm{ml}$ using double distilled water. The mixture was then heated at $80^{\circ} \mathrm{C}$ till blue color appeared and after cooling, the absorbance of blue color was measured at $650 \mathrm{~nm}$ using UV-visible spectrophotometer (Ultrospec 2100 Pro, Healthcare Biosciences AB, Uppsala, Sweden). The content of total phenolics in extracts was quantified using standard curve prepared with different concentrations of tannic acid. The results were expressed as mg tannic acid equivalent (TAE)/g fw of fruit.

The antioxidant activities in methanol extracts of fruit was measured in terms of 2, 2'-azinobis (3-ethylbenzothiazoline-6-sulphonic acid) [ABTS)], 1, 1-diphenyl-2-pycrylhydrazyl (DPPH) radical scavenging and ferric reducing antioxidant power (FRAP) using the methods of Re et al. [7], Liyana-Pathirama et al. [8] and Benzie and Strain [9], respectively. For the determination of DPPH radical scavenging, $1 \mathrm{ml}$ of extract was mixed with $5 \mathrm{ml}$ of $0.04 \%(\mathrm{w} / \mathrm{v})$ DPPH in methanol, mixed properly and the reaction mixture was kept in dark at room temperature for half an hour. The absorbance of mixture was then measured at 517 $\mathrm{nm}$ using spectrophotometer and the results were expressed in $\mathrm{mM}$ ascorbic acid equivalent (AAE)/g fw of fruit.

An equal volume of ABTS salt $(7 \mu \mathrm{M})$ and potassium persulphate $(2.45 \mu \mathrm{M})$ were added for the production of ABTS cation and kept in the dark at room temperature for 16 h. ABTS cation solution was then diluted by using $80 \%(\mathrm{v} / \mathrm{v})$ methanol till an absorbance of $0.70 \pm 0.001$ was obtained. The diluted ABTS cation (1ml) was properly mixed with $1 \mathrm{ml}$ of the extract and kept in the dark for $7 \mathrm{~min}$. The absorbance of this mixture was measured at $734 \mathrm{~nm}$ against methanol blank. A standard curve of various concentrations of ascorbic acid was prepared in $80 \%(\mathrm{v} / \mathrm{v})$ methanol for quantification of antioxidant potential with respect to ascorbic acid. The results were expressed in $\mathrm{mM} \mathrm{AAE} / \mathrm{g}$ fw of fruit.

FRAP assay was arrived out by adding $10 \mathrm{ml}$ of $300 \mathrm{mM}$ acetate buffer $(3.1 \mathrm{~g}$ of sodium acetate and $16 \mathrm{ml}$ glacial acetic acid per liter), $1 \mathrm{ml}$ of $10 \mathrm{mM}$ 2,4,6-tri-2pyridyl-1,3,5-triazine (TPTZ) in $40 \mathrm{mM} \mathrm{HCl}$ and $1 \mathrm{ml}$ of $20 \mathrm{mM}$ ferric chloride. The mixture was pre-warmed at $35^{\circ} \mathrm{C}$. Three $\mathrm{ml}$ of mixture was added to $1 \mathrm{ml}$ of extract and kept at room temperature for 10 min. The absorbance of resulting mixture was read at $593 \mathrm{~nm}$ and the results expressed as $\mathrm{mM} \mathrm{AAE} / \mathrm{g}$ fw of fruit.

The data thus obtained were subjected to SPSS analysis (in triplicates) and mean \pm standard error was obtained. The significant differences between populations and between the raw and ripe fruits were analyzed using Duncan Multiple Range Test and Student's T-test, respectively. The statistical analyses were performed using SPSS software, version 12.

\section{RESULTS AND DISCUSSION}

The results of the present study are shown in Table I and Figure 1. The total phenolic content expressed as mg TAE/g fw was maximum in Kais, followed by Kolibehar, Suind, Sapangi and least in Thalaut population. The effect of population on total phenolic content in methanol extracts of fruit was also found significant at $p \leq 0.001$ (Table 1). The results further showed that changes in the total phenolic content in ripe and raw fruits were insignificant at $\mathrm{p} \leq 0.05$ (Figure 1).

A number of studies have shown that high total phenolic content is associated with greater antioxidant activity [10]-[12]. The variation in total phenolic content and antioxidant activities in fruit extract in the present study may be ascribed to variation in altitude, habitat, vehicular and other emissions. Sharma et al. [2] have reported that plants of the medicinal herb Withania somnifera growing near the roadside contained higher total phenolics than those in the forest. Significant variation in the total phenolic content has been reported in fruits of a wild edible plant Myrica esculenta, and linked to altitudinal variation [13].

TABLE I: TOTAL PHENOLIC CONTENT AND ANTIOXIDANT CAPACITY IN METHANOLIC FRUIT EXTRACTS OF INDIAN OLIVE FROM SELECTED POPULATIONS

\begin{tabular}{|l|l|l|l|l|}
\hline Populations & $\begin{array}{l}\text { Total phenolic (mg } \\
\text { TAE /g fw) }\end{array}$ & \multicolumn{3}{|l|}{$\begin{array}{l}\text { Antioxidant capacity } \\
(\mathbf{m M} \text { AAE/ g fw) }\end{array}$} \\
\hline & & DPPH & FRAP & ABTS \\
\hline Thalaut & $2.30^{\mathrm{c}}$ & $0.20^{\mathrm{b}}$ & $30.54^{\mathrm{b}}$ & $0.0041^{\mathrm{b}}$ \\
\hline Sapangi & $2.33^{\mathrm{c}}$ & $0.21^{\mathrm{b}}$ & $31.43^{\mathrm{a}}$ & $0.0026^{\mathrm{c}}$ \\
\hline Suind & $2.87^{\mathrm{b}}$ & $0.15^{\mathrm{c}}$ & $30.01^{\mathrm{ab}}$ & $0.0138^{\mathrm{a}}$ \\
\hline Kolibehar & $3.24^{\mathrm{a}}$ & $0.17^{\mathrm{c}}$ & $28.02^{\mathrm{b}}$ & $0.0019^{\mathrm{d}}$ \\
\hline Kais & $3.41^{\mathrm{a}}$ & $0.24^{\mathrm{a}}$ & $29.98^{\mathrm{ab}}$ & $0.0045^{\mathrm{b}}$ \\
\hline Average & 2.83 & 0.19 & 30.00 & 0.0054 \\
\hline F-value & 16.55 & 17.46 & 3.34 & 584.53 \\
\hline p & $\leq 0.001$ & $\leq 0.001$ & $\geq 0.05$ & $\leq 0.001$ \\
\hline
\end{tabular}

Values are mean \pm SE of three replicates. Values with different letters (a-c) are statistically different at $\mathrm{p} \leq 0.05$ probability level (Duncan's Multiple Range Test).

The source population and age have significant effect on the antioxidant properties of extracts in ABTS and DPPH assays, whereas, no significant variation in FRAP assay due to population was recorded (Table I and Figure 1). Among populations, antioxidant activities (mM AAE/g fw) in methanolic fruit extracts ranged from $0.15-0.24,28.02-31.4$ and $0.0019-0.0138$ in DPPH, FRAP and ABTS assays, respectively. The results further showed that DPPH, FRAP and ABTS inhibiting potential of fruit extract were highest in Kais, Sapangi and Suind populations, respectively and lowest in Kolibehar population. Rawat et al. [13] have also reported significant variation in antioxidant activities in the methanolic fruits extract collected from $M$. esculenta populations growing at different altitudes. The present study further showed that DPPH and ABTS activities in methanolic extracts were significantly higher $(\mathrm{P} \leq 0.01)$ in ripe fruits as compared to raw fruits, whereas FRAP activity was higher $(\mathrm{P} \leq 0.001)$ in raw fruits in comparison to ripe fruit. This study clearly indicates that both the source population and fruit maturity significantly influence the total phenolic content and antioxidant activities in Indian Olive.

Plant antioxidants have played an important role in maintaining health and providing protection against coronary heart diseases, cancer, etc. Thus, researches on natural antioxidants of plant origin have attracted scientists, food manufacturers and consumers as potential source of functional foods. 

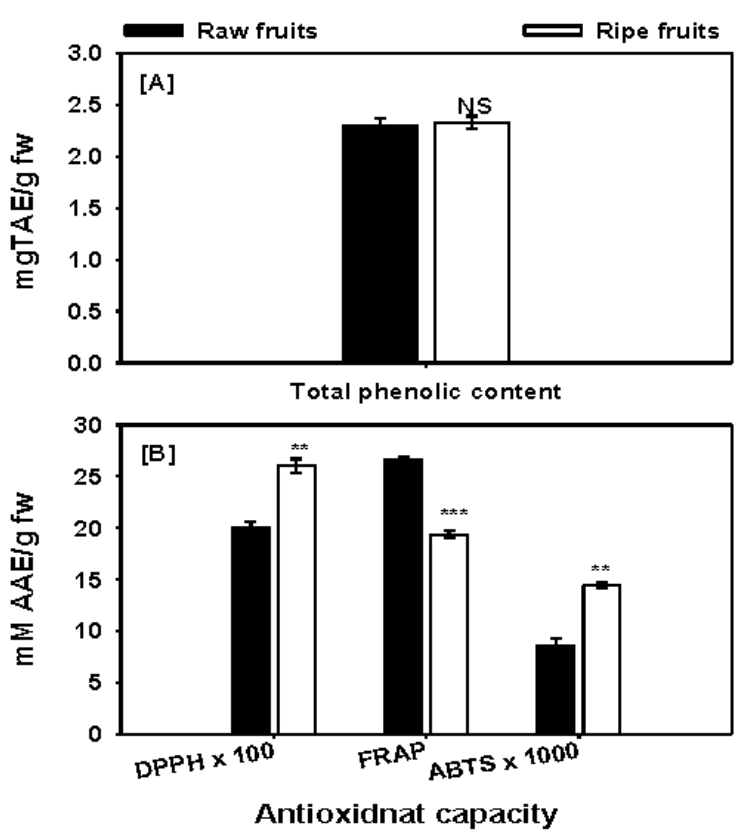

Fig. 1. Total phenolic content $[\mathrm{A}]$ and antioxidant capacity $[\mathrm{B}]$ of methanolic extract of raw and ripe fruit of Indian Olive. Bar with stars in each group is statistically significant (Student's T-test, NS=not significant, $* * \mathrm{p}<0.01 ; * * * \mathrm{p}<0.001)$

\section{CONCLUSION}

The study concludes that ripened fruits of Indian Olive can serve as a source of natural antioxidants for the local population and can also be exploited for commercial purposes However, further investigations on individual phenolic compounds in different plant parts of this species are needed.

\section{ACKNOWLEDGMENT}

The authors are thankful to the Director, G. B. Pant Institute of Himalayan Environment and Development, Kosi Katarmal, Almora, India for providing necessary facilities to carry out the present research work. Financial grant from Ministry of Environment and Forest, Govt. of India, New Delhi is gratefully acknowledged.

\section{REFERENCES}

[1] R. Y. Nasimba, H. Kikuzaki, and Y. Konishi, "Antioxidant activity of various extracts and fraction of Chinopodium quinoa and Amaranthus spp. Seeds," Food Chemistry, vol.106, pp.760-766, 2008,

[2] R. K. Sharma, S. S. Samant, P. Sharma, and S. Devi, "Evaluation of antioxidant activities of Withania somnifera growing in natural habitats of north-west Himalaya," Journal of Medicinal Plant Research, vol. 6, no. 5, pp. 657-661, 2012.

[3] V. Amico, R. Chillemi, S. Mangiafico, C. Spatafora, and C. Tringali, "Polyphenol enriched fractions from Sicilian grape pomace, HPLC-DAD analysis and antioxidant analysis," Bioresource Technology, vol. 99, pp. 5960-5966, 2008.

[4] S .S. Samant and U. Dhar, "Diversity, endemism and economic potential of wild edible plants of Indian Himalaya," International Journal of Sustainable Development and World Ecology, vol. 4, pp. $179-191,1997$.

[5] S. C. Joshi, "Olea ferruginea Royle, Indian Olive: An underutilized fruit tree crop of north-west Himalaya," Fruits, vol. 67, pp. 121-126, 2012.

[6] K. Wolfe, X. Wu, and R. H. Liu, "Antioxidant Activity of Apple Peels," Journal of Agriculture and Food Chemistry, vol. 51, pp. 609-614, 2003

[7] R. Re, N. Pellegrini, A. Proteggente, A. Pannala, M. Yang, and E. C. Rice, "Antioxidant activity applying an improved ABTS radical cation decolorization assay," Free Radical Biology and Medicine, vol. 26, pp. 1231-1237, 1999.
[8] C. M. Liyana-Pathiranan and F. Shahidi, "Antioxidant activity of commercial soft and hard wheat (Triticum aestivum L.) as affected by gastric pH conditions," Journal of Agriculture and Food Chemistry, vol. 53, pp. 2433-2440, 2005.

[9] I. F. F. Benzine and J. J. Strain, "Ferric reducing ability of plasma (FRAP) as a measure of antioxidant power: The FRAP assay," Analytical Biochemistry, vol. 239, pp.70-76, 1996.

[10] W. Zheng and S.Y. Wang, "Antioxidant Activity and Phenolic Compounds in Selected Herbs," Journal of Agriculture and Food Chemistry, vol. 49, pp. 5165-5170, 2001

[11] Y. Cai, M. Sun, and J. Xing, "Structure-radical scavenging activity relationships of phenolic compounds from traditional Chinese medicinal plants," Life Sciences, vol. 78, pp. 2872-2888, 2006.

[12] B. A. Iwalokun, B.U. Efedede, and J. A. Alabi-Sofunde, "Hepatoprotective and Antioxidant Activities of Vernonia amygdalina on Acetaminophen-Induced Hepatic Damage in Mice," Journal of Medicinal Food, vol. 9, pp. 524-530, 2006

[13] S. Rawat, A. Jugran, L. Giri, I. D. Bhatt, and R. S. Rawal, "Assessment of antioxidant properties in fruits of Myrica esculenta: A popular wild edible species in Indian Himalayan Region," Evidence Based Complementry and Alternative Medicine (eCAM), Advance Access Published on May 21, 2010.

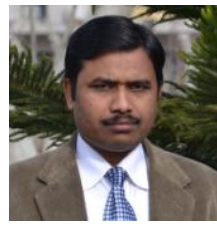

R. K. Sharma was born on February 1, 1978 at Varanasi, India. He has obtained B.Sc., M.Sc. and $\mathrm{Ph}$. D degrees in Botany from Banaras Hindu University, Varanasi, India in 2000, 2002 and 2007, respectively and fellowships from Department for International Development, U.K., and CSIR and France Embassy, New Delhi, India. He is presently working as a Scientist in the fields of food chemistry, plant and environmental biotechnology in G.B. Pant Institute of Himalayan Environment and Development, an autonomous organization of the Ministry of Environment and Forest, Government of India, New Delhi.

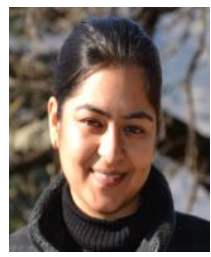

N. Sharma was born on September 8, 1986 at Mandi district of Himachal Pradesh, India and obtained her M.Sc. degree in Biotechnology from HNB Garhwal University, Dehradun, India in 2010. She is currently working as a Junior Research fellow in G.B. Pant Institute of Himalayan Environment and Development, an autonomous organization of the Ministry of Environment and Forest, Government of

India, New Delhi

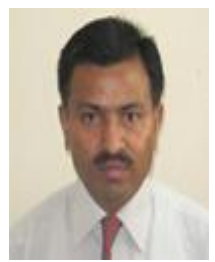

S. S. Samant is associated with G.B. Pant Institute of Himalayan Environment and Development, an autonomous organization of the Ministry of Environment and Forest, Government of India, New Delhi since 1991 as a Scientist. He was born on June 14, 1962 and obtained his Ph.D. degree from Kumaun University, Nainital, India. Presently, He is Scientist In-charge and theme head of Biodiversity Conservation and Management theme of the Institute.

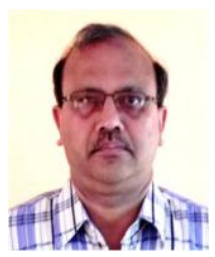

S. K. Nandi is working as a Scientist in G.B. Pant Institute of Himalayan Environment and Development, an autonomous organization of the Ministry of Environment and Forest, Government of India, New Delhi. He was born on June 25, 1958. After obtaining Ph.D. in Plant Cell Biology from the Australian National University, Canberra, Australia in 1988 he was associated with various Institutes researching in the areas of plant physiology, biochemistry and biotechnology; at present he is Group Head of Biotechnological Applications and Biodiversity Conservation \& Management Themes of the Institute.

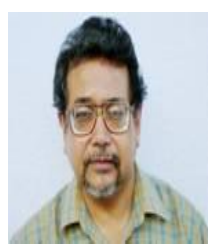

Dr. L. M. S. Palni is the director of G.B. Pant Institute of Himalayan Environment and Development, an autonomous organization of the Ministry of Environment and Forest, Government of India, New Delhi. He was born on May 22, 1953 and obtained his Ph.D. degree from the University of Wales, U.K. His fields of research interest are biodiversity conservation, plant physiology and plant-microbe interactions 